Accepted for publication on 01-May-2019

"This is an Accepted Manuscript of an article published by Routledge Taylor \& Francis Group in [Studies in Continuing Education] on [First published online: 22-May-2019], available online: https://doi.org/10.1080/0158037X.2019.1615424”"

\title{
Young people's agency over continuing education in situations of early job insecurity: from enabling to stumbling
}

Pepka Boyadjieva ${ }^{1}$

Institute for the Study of Societies and Knowledge, Bulgarian Academy of Sciences, Sofia, Bulgaria

1000 Sofia, 13A Moskovska str., Bulgaria

Tel: „,00359“ - „899 $751574 “$

E-mail: pepka7@gmail.com

http://orcid.org/0000-0002-0561-6942

\section{Petya Ilieva-Trichkova}

Institute for the Study of Societies and Knowledge, Bulgarian Academy of Sciences, Sofia, Bulgaria

1000 Sofia, 13A Moskovska str., Bulgaria

Tel: „00359“ - „898907529“

E-mail: petya.ilievat@gmail.com

http://orcid.org/0000-0002-2889-0047

\footnotetext{
${ }^{1}$ Equal authors, the names are listed in an alphabetical order.

Corresponding author: Petya Ilieva-Trichkova, Institute for the Study of Societies and Knowledge, BAS, 13A Moskovska str., 1000 Sofia, Bulgaria. Email: petya.ilievat@gmail.com
} 


\section{Young people's agency over continuing education in situations of early job insecurity: from enabling to stumbling}

Abstract: This article aims to explore how the situation of unemployment and - more generally - early job insecurity affects young people's scope for exercising agency with regard to decisions about continuing and improving their education. Drawing on the theoretical underpinnings of the capability approach, the article develops the concept of patterns of agency regarding continuing education. This concept refers to the mediating processes (interactions with others) whereby young people may convert available resources into new prospects for strengthening their capability to attain education as well as broadening their real choices with regard to education. Relying on information from a wide range of life-course interviews with young people born between 1990 and 1995 from seven European countries (Bulgaria, the Czech Republic, Germany, Greece, Norway, Poland and the United Kingdom), the present study applies the concept of patterns of agency regarding continuing education to the case of young people who have experienced early job insecurity. The analysis reveals the existence of two broad groupings of agency: enabled agency (patterns of realised interactions with institutions and individuals) and stumbled agency (patterns of non-realised interactions with institutions and individuals). The elaborated patterns provide a basis for fruitful future comparative analyses from different perspectives.

Keywords: patterns of agency; continuing education; young people; capability approach; early job insecurity 


\section{Introduction}

Youth unemployment is a widespread phenomenon in Europe and, although there are various initiatives to reduce it (e.g., The Youth Guarantee), its magnitude continues to be alarmingly high. Namely, unemployment rates among young people are double or even more than double compared to general unemployment rates (Eurostat 2017). To a large extent, these rates spiked as a consequence of the economic crisis in 2008; they can also be attributed to widening inequalities across Europe and within European countries regarding skills and living conditions, thus putting young people, especially those with lower levels of education, at risk. A recent comparative study (de Lange, Gesthuizen and Wolbers 2014) shows that the higher the level of young Europeans' education, the less likely they are to experience temporary employment or unemployment; the same study supports the idea that during an economic recession employers transfer labour market insecurities mainly onto lower skilled employees. Still, it seems that little is known about the influence of youth unemployment on young people's scope for exercising agency, e.g., making decisions about continuing their education after either completing or dropping out of formal education. In this respect, it is worth mentioning a report by Ayllon and Nollenberger (2016) focused on how the Great Recession in Europe has changed patterns of young people's schooling decisions. Although the study reveals that young Europeans (especially unskilled ones) are more likely to enrol in education as a response to the poor labour market conditions brought about by the recession, it does not pay attention to either a theoretical understanding of agency or its different manifestations with regard to education. Against this background, the present article aims to explore how the situation of unemployment and - more generally - early job insecurity affects young people's scope for exercising agency with regard to decisions about continuing and improving their education. In other words, we want to understand if and how young people experiencing early job insecurity become learners again after they have left formal education. 
More specifically, we address the following research questions:

1. What are the patterns of agency regarding the continuing education of young people experiencing early job insecurity?

2. Which factors have hindered young people's agency regarding their continued education while experiencing early job insecurity?

The article proceeds as follows. First, we outline the theoretical considerations on the basis of which we identify patterns of young adults' exercising agency with regard to continuing education. Then, we present the research strategy, the data and our main findings. This is followed by a discussion of these findings and conclusions.

\section{Literature review and theoretical considerations}

Recently, there has been growing interest in studying learner agency within different theoretical perspectives (Schoon 2018; Biasin and Evans 2019). Conceptually, the present article draws upon some theoretical underpinnings of the capability approach which are largely attributed to Nobel Prize-winning economist Amartya Sen and were further developed by political philosopher Martha Nussbaum. As Sen $(2009,233)$ puts it, this approach 'focuses on human life, and not just on some detached objects of convenience, such as incomes or commodities that a person may possess, which are often taken, especially in economic analysis, to be the main criteria of human success'and proposes 'a serious departure from concentrating on the means of living to the actual opportunities of living'. In this perspective, living is seen as a combination of various 'doings and beings' (called 'functionings'), while quality of life (well-being) is assessed in terms of the capability to achieve valuable functionings (Sen 1993, 31). Capability refers to ‘a person's ability to do valuable acts or reach valuable states of being' and 'represents the alternative combinations of things a person 
is able to do or be' (Sen 1993, 30). Thus, capabilities and functionings supply two different perspectives through which an individual's position in the social arrangement can be judged: (1) the freedom to achieve and (2) the actual achievement.

There are many critiques to the capability approach, but as Robeyns $(2017,4)$ puts it, '[they] were based either on some scholar's own interest in seeing the approach develop exclusively in a certain direction, or else were based on misunderstandings, often due to miscommunication between different disciplines'. The present analysis emphasises the important fact that none of these critiques stands against the concept of agency. There is one critique worth mentioning here: 'the capability approach is too individualistic'. We agree with Robeyns (2017), who argues that this is not a valid critique against the capability approach in general. Although the capability approach is 'people-centered', Sen himself acknowledges that persons are socially embedded:

The [capability] approach [...] puts human agency (rather than organizations such as markets or governments) at the centre of the stage. The crucial role of social opportunities is to expand the realm of human agency and freedom, both as an end in itself and as a means of further expansion of freedom. The word 'social' in the expression 'social opportunity' [...] is a useful reminder not to view individuals and their opportunities in isolated terms. The options that a person has depend greatly on relations with others and on what the state and other institutions do. (Drèze and Sen 2002, 6)

In addition, by introducing the concept of conversion factors, the capability approach provides a reliable theoretical approach for taking into account both aspects of the social reality - structure and agency. This approach is appropriate for the present study because of three main reasons. First, the capability approach is sensitive to at-risk people and disadvantaged groups. Young people who have experienced early job insecurity may be referred to as such a group. Second, the capability approach views people, even the poor, as active agents (Alkire 2009). Third, in line with other approaches/conceptualisations of agency 
(e.g., Biasin 2018; Biasin and Evans 2019), the capability approach does not focus only on the individual characteristics of agents, but it also acknowledges the social relations and the constraints and opportunities of societal structures and institutions on individuals. In this way, it prevents us from 'victim blaming' when it comes to the actions made by young people who have experienced early job insecurity regarding their continued education. Thus, in contrast to other studies, the capability approach offers a fruitful viewpoint from which to rethink education and lifelong learning (e.g., Walker and Unterhalter 2007; Boyadjieva and IlievaTrichkova 2018).

\section{The concept of agency through the capability approach lens}

The concept of agency implies a defined space characterised by freedom and within which people can act. In contrast to capability, which refers to the opportunity aspect of freedom, agency 'relates to personal process freedoms'(Alkire, Qizilbash and Comim 2008, 4). An agent 'is someone who acts and brings about change, and whose achievements can be judged in terms of her own values and objectives, whether or not we assess them in terms of some external criteria as well' (Sen 1999, 19). Agency is related to the ability to pursue and realize the goals that one values and has reason to value (Alkire and Deneulin 2009). However, the ability to pursue valued goals needs not be advantageous to the agent alone. Agency can be self-regarding but also other-regarding (Crocker and Robeyns 2009). Similarly to well-being, two aspects of agency can also be distinguished: freedom and achievement. Whereas 'agency freedom' is related to the 'freedom to bring about the achievements one values and which one attempts to produce' (Sen 1992, 57), the achievement of a person's agency 'refers to the realization of goals and values she has reason to pursue, whether or not they are connected with her own well-being' (Ibid., 56).

In fact, it is precisely by taking note of agency achievements or agency freedom that 
the capability approach can shift the focus away from seeing people as just vehicles of wellbeing and ignoring the importance of their own judgments and priorities where agency is concerned (Sen 2009). Such an understanding of agency stresses people's active role and capacity to change and transform reality in accordance with their own conception of the good, once this conception has passed beyond reasoned scrutiny. However, although agency implies a certain measure of individual responsibility, it does not lead to the trap of blaming the victim, given that agency in the capability perspective acknowledges human diversity and the wide range of factors which enable, or constrain, a person's ability to exercise his or her agency in practice/reality. This implies that different people have different capacities to transform their resources into real agency freedom or achievements.

In order to understand people's agency, we need to know more about the context and structures people are embedded in. As Wilson-Strydom (2015) emphasises, it is the manner in which this approach binds agency together with the interaction of agents and social contexts that potentially breaks new ground. The conceptual device used to bring together structure and agency is the notion of conversion factors. These factors influence how a person can be, or is, free to convert the characteristics of a given good or service into freedom or an achievement. Different authors propose different classifications of conversion factors (Sen 1999; Robeyns 2005; Crocker and Robeyns 2009). We accept that the basis of the classification of conversion factors should be the level they operate on: micro, meso or macro (see Dingeldey et al. 2015). This classification has specifically been drawn in order to make a comparative assessment of the consequences of early job insecurity and labour market exclusion across different labour market contexts. We have used it because it is in line with our view that participation in lifelong learning is a layered problem. As Boeren (2017) suggests, by acknowledging that there are different layers and nested structures of lifelong learning which operate at micro, meso and macro levels, we can better understand why people 
do or do not participate in lifelong learning activities or, in our case, the patterns of agency regarding continuing education.

\section{Brief overview of educational research within the capability approach which considers the} concept of agency

Agency implies the active role of people in all spheres of life, including education. As Walker and Unterhalter (2007) emphasise, embracing agency in and through our education practices allows us to open up the possibility of interrupting a pervasive relationship in education that tends to link learners' origins and outcomes. In this regard, when trying to measure girls' capabilities in formal school settings, Vaughan (2007) distinguishes two types of capabilities: capabilities to participate in education (these are the capabilities of children within the educational experience) and capabilities gained through education. Whereas the former refers to the freedom of a child to fully participate in the school-learning process, the latter are associated with the contribution of education to other life functionings, as opposed to purely educational functionings. Vaughan (2007) emphasises that, in contrast to the compulsory education on which her study is focused, adult and higher education would potentially involve a much higher level of well-being and agency freedoms.

Rubenson and Desjardins (2009) incorporate the capability approach into a model which they term 'Bounded Agency'. Their model implies that the welfare state regime can affect a person's capability to participate in adult education through the way it constructs material, social and institutional environments, the way these result in situational and institutional, or structural, barriers, and a person's internal state of readiness as expressed through dispositional barriers. This model has been applied by Roosmaa and Saar (2016) in a cross-national European analysis of the barriers perceived by adults who do not want to participate in learning. Their results confirm the significance of including structural and 
institutional factors in addition to individual characteristics in order to explain barriers to adult learning and indicate substantial country differences between all types of barriers perceived.

Obviously, these factors exert their influence on personal agency regarding educational prospects, and this should also be studied in further depth.

In her study on widening participation in higher education, Walker (2007) talks specifically about lifelong learning as a capability. Using Nussbaum's list of ten central capabilities, she identifies four lifelong learning capabilities, none of which can be reduced to any of the others: practical reason, affiliation, emotions and imagination. These capabilities offer a guide to what information we need for evaluating how well students are doing as part of widening participation and as they develop their agency and well-being in and through higher education. Generally speaking, people in education are the agents of their own learning, the agents or instruments of the learning (or failure to learn) of others and the recipients of others' agency (Walker and Unterhalter 2007). This appears to also lend relevance to situations of lifelong learning, wherein students are the subjects of their own actions to the extent that their inclusion in education can only occur as a result of their personal choices, although their actions can be mediated by others' agency, especially if they belong to a disadvantaged group.

\section{A theoretical framework of agency regarding continuing education}

Taking into account the above theoretical discussion, we outline a theoretical framework for studying agency regarding continuing education. Young people who continue their education after finishing or dropping out of formal education are involved in different forms of learning, which includes diverse kinds of knowledge and skills (institutionalised and informal, organised and sporadic, purposeful and unintended) within different perspectives (personal 
and social; employment and citizenship; leisure and work) (Boyadjieva and Ilieva-Trichkova 2018).

We develop the concept of patterns of agency regarding continuing education. We define these patterns as the mediating processes (interactions with others) whereby young people may convert available resources into new prospects for strengthening their capability to attain education as well as broadening their real choices with regard to education. As mentioned above, we will focus on the conversion factors at the micro, meso and macro levels. Examples of conversion factors at the micro level related to continuing education are gender, age, ethnicity and level and type of skills. Factors at the meso level could be regional/local institutional educational arrangements, the state of the local economy or employers' perceptions and practices; whereas factors at the macro level include various national institutional arrangements in the sphere of education, macroeconomic conditions and economic structures. Thus, by taking the above conversion factors into account, the capability approach allows for the consideration of not only individual characteristics in evaluating inequalities in education, but also the institutional and macro-level features of the contexts where these inequalities are analysed. A similar understanding has already been applied to adult participation in lifelong learning, but only at the theoretical level and within a different theoretical perspective. More specifically, Boeren (2017) discusses this participation in her recent study as a problem affected on different levels (micro, meso and macro) which function within a layered structure. However, no emphasis is given to the patterns of agency which may be adopted by young people with regard to continuing their education. In our framework, each mediating process might broaden or narrow young people's achieved functionings. In other words, conversion factors can either enhance or constrain people's effective freedom (Hvinden and Halvorsen 2017). This may respectively reflect on a variety of actions related to adult education (such as going back to school, enrolling in different courses, being involved in 
workplace learning, etc.), no actions or merely stumbled attempts at actions. Depending on the actions adopted, they may lead to people's improved capability sets or the deterioration thereof. It is also possible that these actions may not cause any changes in the capability sets of people regarding their education at all. For an actor to transform a capability set into an agency achievement as part of continuing education, an act of choice is necessary. This choice depends not only on the range of opportunities people have but may also reflect differences in the actor's goals and the particular things he/she values. Sen (1992) outlines that a person's agency achievement refers to the realisation of goals and values she has reason to pursue, whether or not they are connected with her own well-being. With respect to continuing education, agency achievements may include improving knowledge and skills, raising selfconfidence, empowering one to control her/his environment, etc.

We apply our theoretical framework of agency regarding continuing education to young people in situations of early job insecurity. Although authors differ in their definitions of job insecurity in its concrete dimensions, they all associate it with difficulties in transitioning from school to work, increased frequency of young people losing their jobs and incomes and more precarious work being offered (part-time jobs and temporary contracts, especially involuntary ones) (De Witte and Näswall 2003; Chung and van Oorschot 2011). De Witte and Näswall (2003) highlight that psychological research favours the study of job insecurity as the perception of employees. However, the literature also contains other interpretations. Thus, for instance Bussing (1999) pleads for a clearer distinction between job security as both objective and subjective phenomena. Acknowledging previous research, in this article we use the understanding of job insecurity as an objective phenomenon which is associated with the threat of losing one's job and income as well as falling into situations of social and economic vulnerability which highly limit one's resources. 


\section{Research strategy and empirical basis}

Based on our theoretical considerations, we first define several criteria for identifying different patterns of agency regarding continuing education among young people who have experienced early job insecurity. Second, applying these criteria to our empirical basis - the life-course interviews - we reveal different patterns of young people's agency. Third, we describe the identified patterns and use them as an analytical prism through which concrete life-course trajectories can be understood.

It is believed that agency cannot be defined outside of its relation to goals (Alkire 2009). However, we argue that it can also be defined in relation to the mediating processes through which young people advance the realisation of their goals. Thus, given the importance of resources and capability inputs and their role of mediating the scope of agency among young people experiencing early job insecurity, as well as the extent to which they manage to convert their resources and capability inputs into agency achievements or not, we introduce two main criteria for identifying different patterns of early job insecurity's effect on young people's scope for exercising agency with regard to education:

1. What are the essential interactions with others (institutions and individuals) whereby young people have been able to exercise agency in situations of early job insecurity?

2. Have young people succeeded in converting their resources into agency achievements related to education and, if so, how?

The study is based on data from 81 semi-structured life-course interviews with young people belonging to the birth cohort 1990-1995 in seven European countries: Bulgaria (BG), the Czech Republic (CZ), Germany (GER), Greece (GR), Norway (NO), Poland (PL) and the United Kingdom (UK). These interviews were conducted between May 2016 and November 2016 within the Horizon 2020 project NEGOTIATE: Overcoming Early Job-Insecurity in 
Europe (https://negotiate-research.eu/) as a part of a larger study. In order to qualitatively examine early job insecurity experiences, an interview guide was developed and pre-tested in each country. This guide was drafted based on previous research in the field and the theoretical perspectives relevant for the larger project, including the capability approach. The interview guide was thematically organised with the aim of investigating unemployment narratives framed within people's life stories. It included questions about the transition from school to unemployment and how unemployment affected interviewees' life situations. There were questions about opportunities to be active during unemployment and benefit from support (from family, non-governmental organisations, the government) and the activities undertaken during unemployment. It is important to emphasise that the questionnaire included a series of questions about respondents' educational background and the educational activities undertaken by them during and as a consequence of their unemployment experience. The interview started with questions about respondents' biographies, families, education and current employment situations and continued with more sensitive and abstract questions. After approval, the guide was translated into the participating countries' languages.

The recruited interviewees had to fulfil the following criteria in order to be interviewed: they had to have experienced unemployment or job insecurity by the time they were 25 years of age; and they must not have attained tertiary education before turning 25 . Thus, we have used two objective criteria for defining job insecurity. The reality on the ground is that people often go through repeated instances of short unemployment, precarious employment, staying at home with caring responsibilities, etc., rather than being completely out of work. People go in and out of casual work and temporary jobs. The data indicate that many young unemployed Europeans are participating in the shadow economy, as in Bulgaria, for example. The interviews there showed that non-contractual employment is part of the working experience of many young people. It was agreed that these very common experiences 
should not be excluded from the study, although the main emphasis remained on the longterm unemployed. All interviewees were aware of the purpose of the project and signed an informed consent form which was approved by the Norwegian Centre for Research Data and local and university ethical committees, where necessary.

The interviews were conducted by experienced researchers who were either members of the research team or hired for the job. For those who were hired, briefings were organised to clarify all details regarding the use of the interview schedule. The interviews lasted between 30 minutes and 2 hours. Almost all interviews were sound recorded. A transcript in the national language and a synopsis in English were made for each interview. In addition, national summaries were prepared by each research team. To protect the anonymity of the interviewees, we refer to them using pseudonyms and indicating their country and gender: for instance, Ani (BG Female) (More details on the methodology can be found in Tolgensbakk, Vedeler and Hvinden 2017).

Although we have collected rich, extensive and heterogenous data, we acknowledge that they have some limitations. First, the number of interviews carried out differed by country - between $7(\mathrm{NO})$ and $16(\mathrm{CZ})$ interviews with young people from the birth cohort 1990-1995 were conducted in each country. Second, although the national samples had some common characteristics (e.g., the samples were gender balanced), they differed in relation to ethnic composition, place of residence and the health status of interviewees. Thus, the Bulgarian and Czech samples included some representatives of ethnic minorities (in the Czech sample, 4 out of 16 interviewees were Roma; in Bulgaria, 3 out of 14 were Roma; in Greece, there were no interviewees from ethnic minority groups). In the Norwegian sample, there were 3 interviewees with disabilities, whereas the German sample did not include any disabled people. The Norwegian sample included 3 people living in villages and small towns compared to 5 out of 10 in the German sample, while all the young people interviewed in the 
Greek sample lived in the capital city. Third, we analysed the extended summaries of the interviews rather than the full transcripts. Fourth, the interviewees in each country are not statistically representative of all unemployed persons in those countries. However, the interviewees and the rich narrative data they have given us do represent a comprehensive range of all the important groups of unemployed youth in Europe.

In order to ensure the validity of the results, we have followed a methodological procedure which envisages their constant verification in which the two authors make a comparative analysis both separately and together. We have carried out a two-step analysis of the interviews. For the first stage, both authors read the synopses of the life-course interviews independently. We used the above theoretical considerations and the two criteria as the analytical prism through which to view the life-course interviews. More specifically, our task was to identify the mediating processes through which young people convert available resources (initial conditions) into new prospects and the scope for real choices with regard to continuing education. We each compiled a list of the institutions and individuals with whom young people interacted when trying to overcome early job insecurity and indicated whether this interaction had positively influenced the individual's engagement with educational pursuits. For the second stage, we compared the interactions with others (institutions and individuals) which we had identified separately. There was about a 90 percent coincidence in the identified interactions. The common interactions with others were selected and classified into different patterns within the two broad groupings of agency: enabled agency (patterns of realised interactions with institutions and individuals) and stumbled agency (patterns of nonrealised interactions with institutions and individuals).

\section{Results}

\section{Patterns of exercising agency with regard to continuing education}


Within the two groups of patterns - enabled (realised) and stumbled (not realised) agency we identified the following different types.

Enabled agency: Patterns of realised interactions with institutions and individuals

- Self-relying agency

- Institutionally-supported agency:

○ State institutions

○ NGOs

- Informally-supported agency:

- Family and relatives

$\circ$ Friends and networks

- Social commitment-supported agency

Stumbled agency: Patterns of non-realised interactions with institutions and individuals

- Disoriented and unmotivated agency

- Hampered agency (at micro, meso and macro levels)

- Blocked agency

The identified patterns represent ideal types in a Weberian sense. The patterns indicate essential social interactions through which agency is (im)possible in the situation of early job insecurity. Similarly to Biasin and Evans (2019), who have identified patterns of relationship among identity, agency and learning, we do not consider our patterns as the moral labelling or judging of people; we rather use them to indicate the recurrent pattern of responses in the interviews.

Description and empirical manifestation of the identified patterns of agency with regard to continuing education 
Below, we provide a short description of the identified patterns and use them as an analytical instrument to describe and understand the scope of young people's agency regarding their continuing education in situations of early job insecurity.

\section{Patterns of realised agency}

Self-relying agency. This pattern refers to young people in situations of early job insecurity who manage to convert their initial conditions by undertaking different actions while relying mainly on themselves, not on support from state institutions or informal circles. They are successful in widening their capability set and, using it as a base, achieving improved prospects for education.

Philippa (GR Female) finished a two-year vocational programme in hairdressing. She worked as an apprentice in a hair salon for two months. She then worked in another hair salon for a year and a half. She did not receive a salary there, only tips. She was disappointed with the behaviour of her employer and felt exploited. She was treated badly and for that reason she decided to change fields; she is currently attending a vocational school of economics. She is now doing a paid internship in public service... She is planning to finish school and work in an accountant's office.

Institutionally-supported agency. This pattern refers to young people who, in situations of early job insecurity, manage to convert their conditions by undertaking different actions with the decisive support of different institutions, such as state employment agencies and NGOs. They succeed in negotiating institutional support and taking advantage of it. Thus, they manage to widen their capability set and, based on this, achieve improved prospects in relation to education. 


\section{○ State institutions}

The state employment agencies and labour offices are the main state institutions legally obliged to support young people during unemployment by providing information and guidance and offering trainings and jobs. Institutional support from state institutions can thus widen young people's scope for agency in two ways: by helping them cope with financial problems during unemployment and by providing them with various options related to training. The most important issue regarding state-supported agency in relation to education refers to the relevance of training courses offered, both according to individual interests and labour market demands. Depending on its usefulness, a training course could serve as either a bridge to employment or a 'waste of time' for the young people involved in it.

Eva (CZ Female) is satisfied that the labour office employees have always acted fairly and helped her look for a suitable (not just any) job. She thinks that the people in the labour office did what they could for her. . . Although she regrets having taken a bartending course and wishes she had taken an English or IT course instead, she perceives it as something positive that the labour office is paying for these courses and giving people the opportunity to learn new things.

Bogdan (BG Male) has looked for work through the Employment Office several times. 'Five times I've registered.' He does not feel satisfied by the work of the officials there. 'Instead of looking for a job for me, they sign me up for courses. Last year, they signed me up for a conflict management course.' Although he has not started work through the Office, the respondent shares that (in the course), 'they taught me how I should communicate with people, not to quarrel'.

○ NGOs 
NGOs appear to be an important institutional actor for young people born in the 1990s. By taking part in activities and programs organised by NGOs, young people in situations of early job insecurity manage to widen their capability sets not only by acquiring new knowledge and experience, but also by changing their values, goals and life orientations. Young people's interactions with NGOs improve the scope of their agency mainly because young people become involved in meaningful and socially-sensitive activities, thus building their capacity for agency that is not only self-regarding but also other-regarding.

One of the organisations of which Ivo (BG Male) is a member hired him under a trainee program for young people over a period of six months; he assessed this support as very significant for him with regard to his professional orientation: 'Well, while I worked in the $N G O$, I communicated with people as an educator and it gave me some confidence that I can do this, that I can work with children so as to have some influence on young people and ... little by little I started ... [And you acquired confidence?] Yes.' Another NGO, which mostly functions as a special interest club, also gave him support, engaging him to teach painting to children on a voluntary basis - his payment was in the form of donations from parents.

Informally-supported agency. In situations of early job insecurity, interactions with informal circles - family, relatives, friends and social networks - are very important mechanisms through which young people try to overcome crises (both material/financial and psychological) and convert their available resources into new prospects with regard to education. The functioning of this pattern is determined by the fact that it is based on informal, intimate and highly emotional interactions. Thus, when young people have reliable and strong connections with their informal circles, they can rely on them over and over again and in different situations. This widens young people's scope for agency and provides a safety net to protect them from the negative consequences of early job insecurity. Conversely, young 
people who have broken relationships with their families and friends risk 'falling into a vacuum' and giving up when interactions with official institutions turn out to be ineffective and/or counterproductive (see hampered agency).

\section{○ Family and relatives}

Family and relatives can widen young people's scope for agency in situations of unemployment and life uncertainty in various ways: by ensuring their sustenance and thus freeing them from the burden of 'surviving without any money' (offering a home for free as well as financial support), by providing emotional support and advice and by seeking out and finding training offers. Thus, the family turns out to be the main safety net and a main source of social resilience for these youth. Due to periods of early job insecurity, or for lack of financial resources, many young people postpone leaving home.

\footnotetext{
After raising two of her children, Desislava (BG Female) decided to continue her education in a direction other than economics, which she had studied in high school. She enrolled in higher education in the capital city and is currently studying pedagogy as an extramural student. When she failed to enrol in higher education immediately after completing high school, getting out on the labour market and starting to look for work, she began to despair and no longer had such a strong desire to study at university. Thanks to the support of her family, Desislava 'gathered strength' and began to study in higher education.
}

\section{○ Social networks and friends}

Young people's social capital - their social networks - is an important factor which can positively influence their scope of agency in situations of early job insecurity in various ways: by motivating young people to act, by orienting their actions and by supporting young people both financially and emotionally in their actions. The wider the social network of a 
young person, the greater the possibility it will enlarge their scope for action and opportunities for choice. However, social networks can mediate the involvement of young people not only in socially-relevant and personality-developing actions, but also towards unsocial and risky behaviours.

Gabriele (GER Female) has filled out numerous applications throughout Germany. In addition, she completed internships using the assistance of acquaintances. Relatives and friends also arranged internships for her.

Social commitment-supported agency - volunteering. This pattern refers to young people who, in situations of early job insecurity, manage to enhance their capability set by engaging as volunteers in causes and activities. Asa process of involvement in activities without pay, volunteering is a transformative and empowering experience. People cannot be forced to volunteer - they become volunteers by their own free will and are committed only to activities they view as meaningful. Volunteering empowers people by increasing their experience, knowledge, confidence and social capital.

Stig (NO Male) has been active in trying to find (volunteer) organisations where he can find help and support. He has been a regular at a resource centre for people experiencing mental health problems: "I found it myself. While I was still at the art college, I started hanging out at a place targeted at people with severe learning disabilities. That way, I had someone to talk to. And then I asked if they knew of somewhere that suited me. Where I could get some help. Just a place to be. So, they mentioned some places, and I Googled a bit and [thought] 'no, that's not it', but then I visited the centre." 
Josh (UK Male) took cash-in-hand jobs for a few weeks or days and then claimed Jobseeker's Allowance. The Job Centre had required him to do voluntary work to maintain his benefits and he worked in a charity shop, which he found to be a positive experience. He said that he had 'come out of his shell' during a spell of voluntary work where he gained 'confidence and people skills'.

To sum up, our analysis of the 81 semi-structured life-course interviews showed that each of the patterns of realised agency regarding continuing education led to and involved different actions and resulted in different agency achievements (see Table 1).

[Table 1. Type of actions and agency achievements with regard to continuing education, near here]

We emphasise that we did not find a one-to-one link between the actions and agency achievements; that is, each of the actions could lead to any one of the identified agency achievements.

\section{Patterns of stumbled agency}

These patterns refer to young people who are not able to convert their initial conditions into improved prospects in relation to education. Their scope of action is very limited, either because they do not have clear goals or due to other constraints outside of their control. Thus, their attempts at action are constrained; and even when they undertake some actions, these are somehow disoriented, do not contribute to widening their capability sets and do not improve their well-being in the sphere of education. 
Disoriented and unmotivated agency. The main characteristic of this pattern of agency is that young people are unable to formulate clear, high-value goals to pursue. This pattern seems to be widely spread across the group of young people experiencing early job insecurity. For instance, many of the German interviewees did not really have an idea of what they wanted to do after school, or they had unrealistic ideas about their futures, such as becoming an actor or a fashion model. A lot of young people broke off their vocational training or cancelled employment contracts after completing vocational training because they felt that this was not the right path for them. The degree of life orientation of some interviewees was quite low when they were young. In such cases, these young people mostly suffered from a lack of (career) guidance to make their goals clearer or more realistic and help them envisage new prospects.

Annaliese (GER Female) failed to complete her upper secondary school certificate. Later, she could have completed vocational training. But she does not want to work in the respective profession. Due to her lack of a concrete alternative professional orientation, she does not consider attempting training.

Emilie (GER Female) has a lower secondary school qualification. She assesses her career opportunities to be low. However, due to educational requirements, her family situation and a still only partially existent vocational orientation, completing further qualification is not feasible.

Hampered agency. The main characteristic of this type of agency is that it is limited due to factors at various levels.

$\circ$ At the micro level 
One's agency related to education can be limited and hampered by a variety of micro-level factors, ranging from family responsibilities and troubles (having children or early/single parenting, family conflicts or illnesses) to personal problems (deviant behaviour, use of drugs, illness, lack of confidence, low aspirations). The scarring effect of these factors can be so strong that it constrains one's scope of action to the extent that one lacks the sufficient capacity to deal with them.

Adléta (CZ Female) finished primary school at 15 and fell pregnant at 16, halting her further education. She also explained that both her aspirations and prerequisites to educate herself were minor, since she comes from a large Roma family where most members are unemployed, living in poor housing conditions and have no aspirations for education.

Dieter (GER Male) left school with a lower secondary school certificate. Due to personal problems (right-wing scene, crime, illness), he does not consider taking on training.

One year after completing secondary education, Hynek (CZ Male) continued for half a year in higher education (at a private school where the requirements are not as high as in public universities) studying economics, but had to quit because of family problems: his mother could not work anymore due to illness and he had to earn money.

○ At the meso level

In a number of cases, the capacity of state institutions to empower young people to act and widen their capability sets turns out to be problematic. Many young people assess the institutional support supplied by the employment offices as too low, unsuitable, irrelevant or even counterproductive. In particular, job counselling and remedial classes are viewed as most unhelpful. 
Samuel (UK Male) did briefly try to get back into education to earn better qualifications between the ages of 19 and 20. But when he returned, the teachers used the same old memorisation techniques that did not appeal to him. So, he left.

People in the unemployment office never asked Petr (CZ Male) what he wanted or needed. They just gave him information. 'I never received much help from the state institutions and I never thought they could be helpful. I have a lot of bad experience.' They offered him no requalification, even though he asked about it. 'I wanted to do requalification in IT, but they discouraged me from even applying. They said it was too difficult to get there and that this requalification is intended for those who already have a job in IT.'

- At the macro level

Last but not least, agency can be hampered by factors at macro-level: related to national educational polices, the country's educational system and available educational offers/infrastructure.

Anders (NO Male) went on to teacher education in a different part of the country. He quit that educational path after finding the study program irrelevant and, in addition, stated that the tendencies in educational policies do not fit his view of being a teacher.

As long as Theofanis (GR Male) sees that educated people are unemployed, too, he feels sure and confident that there is no need to improve his qualifications or skills. He believes that he has coped well with his life so far.

Table 2 systematically presents the main factors that hinder young people's agency with regard to continuing education. 
[Table 2. Factors hindering young people's agency with regard to continuing education at the micro, meso and macro levels, near here]

It should be emphasised that these factors influence young people's agency in countryspecific ways. The interviews also suggest that there might be differences in the way these factors influence the agency of young people belonging to different generations, places of residence and genders.

Blocked agency. This pattern refers to a situation of unemployment that absolutely "paralyses" and dispirits young people. They fall into prolonged periods of despair and depression without being able to undertake any actions to improve their situations. Young people feel helpless to overcome situations of early job insecurity, and every failure to do so further demotivates them. A hurdle arises at every step of their actions toward achieving their goals. This pattern often goes hand-in-hand with deteriorated mental well-being or health problems. In the Norwegian material, the interviewees tie these constraints on agency mainly to health issues and the lack of appropriate services from the Norwegian labour and welfare administration (NAV). Therefore, the majority of these people suffer foremost from a lack of psychological/medical support.

When Lulu (UK Female) finished secondary education, she went straight to a college in the city, but dropped out less than halfway through her AS-level year due to mental health issues. These issues stemmed from being 'bullied quite badly' and having had 'a difficult time at home' while in school. Lulu believes that going to college immediately after secondary school was too much for her, due to her agoraphobia and anxiety over using public transportation to commute to the college. 
In conclusion of this section, we would like to emphasise that in many of the cases studied, two or more interactions co-existed and produced combined patterns. Namely, some young people in situations of early job insecurity have benefitted from both volunteering (agency enabled by social commitment) and state or family support, while others have been hampered by factors at both the micro and meso levels.

\section{Discussion of the results and conclusions}

The article contributes to previous research in a number of ways. Firstly, it demonstrates the heuristic potential of the capability approach for conceptualising and understanding agency with regard to continuing education in the concrete case of young people who have experienced early job insecurity. Secondly, drawing on the extended summaries of life-course interviews of young people, it identifies not only patterns of realised agency in relation to continuing education, but also defines patterns of stumbled agency. We apply these patterns to young people who have experienced early job insecurity, but they can be used for understanding agency regarding the continuing education of other groups, as well. Thirdly, it reveals factors hindering young people's agency at micro, meso and macro levels. Fourthly, it identifies types of actions and agency achievements with regard to continuing education for young people who have experienced early job insecurity. Fifthly, the article further widens the scope of application for the capability approach in studying education by using it as a theoretical framework to reveal various possibilities for agency, and thus empowerment, of a specific vulnerable group in Europe (young people experiencing early job insecurity) not only through formal but also through non-formal education.

Our article is in line with Hvinden and Halvorsen's recent study (2017), whose main argument is that the capability approach can enrich sociology's capacity to link human agency and structure in dynamic analyses of social inequality and marginality. Relying on the 
concepts of conversion processes and factors, the authors outline a model of agency-structure dynamics and the mechanisms through which the linkages between agency and structure are likely to emerge, reproduce or change. The conceptualisation proposed in this article outlines a non-dynamic framework, and as such it is more consistent with Robeyns's scheme of the capability approach (2005). In contrast to the latter, though, our main emphasis is on agency and is drawn from the particular cases of young people who have experienced early job insecurity.

Our study comes along with some peculiarities. As already pointed out, it is based on qualitative data and non-representative samples. Furthermore, the identified patterns were constructed from certain elements of the life courses of our interviewees but are not entirely encompassed by any of our interview cases. It is also important to emphasise that we have studied agency in relation to education within a longer span of young people's life courses. That is why it is possible, in different stages of a single life course, for one pattern to be followed by another; young people might also follow shifting trajectories with regard to finding different kinds of education.

The elaborated patterns of young people's agency in relation to continuing education provide a basis for fruitful future comparative analysis from different perspectives and in response to various questions, the most important of which are: 1) Do patterns of youth agency in relation to continuing education differ between countries, i.e., in different institutional contexts?; 2) Do patterns of youth agency differ between cohorts/generations, i.e., in different historical contexts?; and 3) Do young women and men have different patterns of agency? Our results clearly demonstrate that the patterns of agency regarding education among young people in situations of early job insecurity are embedded within national and institutional contexts. Thus, for example, we have found many cases of social commitmentenabled agency (volunteering) in Norway and the UK but only rare cases in the other 
countries studied. This pattern is also more pronounced among women. The patterns of agency enabled by family and relatives and otherwise informally-enabled agency seem to be equally represented in all countries and between women and men. Institutionally-enabled agency appeared to have a less pronounced role in Greece and Bulgaria than in Norway and was also less evident among men than among women. Further research is needed to show the magnitude of these patterns in each country and to explain the revealed differences between countries with regard to the identified patterns of agency. It is worth exploring the heuristic potential in this respect of some country typologies, e.g., welfare regimes, youth transition regimes and learning and training systems.

A recent paper (Boeren and Whittaker 2018) presents and discusses a new sevencategory typology of adult educational provisions available to the lowest-educated adults in society: (1) basic skills and basic education, (2) a second chance education at upper secondary levels, (3) post-secondary VETs, (4) apprenticeships, (5) training that forms part of Active Labour Market Policies, (6) workplace or job-related learning and (7) personal or social learning. Further research could also test whether there is a link between a given pattern of agency and the type of continuing education. For instance, we could verify if state institutions support mainly job-related training and if NGOs support personal or social learning.

Drawing on rich, qualitative data, the article has shed light on- the restlessness of young people and the various strategies they pursue to advance their education. Early job insecurity turns out to be a serious predicament - and even a 'roadblock' - for the scope of agency and resilience of people. Although our main focus was on actions and agency achievements, in many cases they were not enough to improve people's life situations or, more importantly, to enable people to acquire a feeling of well-being and realise valued and meaningful achievements in relation to their education. However, we believe the reasons why certain agency achievements do not lead to well-being achievements is a matter for further 
research to explore. Our analysis of the patterns of agency in relation to continuing education has demonstrated that young people can hardly get out of the vicious circles in which they find themselves, thus feeling vulnerable to labour market exclusion. Even in cases where people manage to continue their education, it is not always the education they value or view as worth pursuing. Still, the extent of these trends in different countries ought to be further tested.

The elaborated patterns of young people's agency in relation to continuing education provide a basis for identifying points of intervention when attempting to overcome early job insecurity among youth across Europe. Thus, our study raises an important policy question: How can youth be empowered to interact and negotiate with different institutions in such a way that they might be able to more successfully convert available resources (initial conditions, which are highly constrained in periods of early job insecurity) into new prospects and the scope for real choice with regard to education? Our study also points to the need for elaborating policies - both at the local and national levels - that directly or indirectly have a positive effect on people's capability to become educated, i.e., to choose a personally-valued form/type of education at any stage of their lives.

\section{Acknowledgements}

We would like to thank the anonymous reviewer and the editor for their valuable comments on an earlier version of this article.

\section{Funding}

This work was supported by the Bulgarian Ministry of Education and Science under the National Research Programme 'Young scientists and postdoctoral students' [grant number 
DCM \# 577 /17.08.2018] and by the ENLIVEN project funded by the European Union (EU),

Horizon 2020 research and innovation program under [grant number 693989].

\section{References}

Alkire, S. 2009. “Concepts and Measures of Agency.” In Arguments for a Better World. Essays in Honor of Amartya Sen. Volume I: Ethics, Welfare, and Measurement, edited by K. Basu and R. Kanbur, 455-474. New York: Oxford University Press.

Alkire, S., and S. Deneulin. 2009. "Human Development and Capability Approach." In An Introduction to Human Development and Capability Approach: Freedom and Agency, edited by S. Deneulin and L. Shanani, 22-48. London and Steling: Earthscan.

Alkire, S., M. Qizilbash, and F. Comim. 2008. "Introduction.” In The Capability Approach: Concepts, Measures and Applications, edited by F. Comim, M. Qizilbash and S. Alkire, 1-25. Cambridge: Cambridge University Press.

Ayllon, S., and N. Nollenberger. 2016. Are Recessions Good for Human Capital Accumulation? NEGOTIATE working paper no. 5.1. Available at: https://negotiateresearch.eu/files/2015/04/NEGOTIATE-working-paper-no-D5.1.pdf

Biasin, Ch., and K. Evans. 2019. “Agency, identity and learning at turning points in women's lives: A comparative UK-Italian analysis.” European Journal for Research on the Education and Learning of Adults 10 (1): 47-63. DOI 10.3384/rela.20007426.RELA915.

Boeren, E. 2017. "Understanding adult lifelong learning participation as a layered problem." Studies in Continuing Education 39 (2): 161-175, DOI:10.1080/0158037X.2017.1310096. 
Boeren, E., and S. Whittaker. 2018. “A Typology of Education and Training Provisions for Low Educated Adults: Categories and Definitions." Studies in the Education of Adults 50 (1): 4-18, DOI: 10.1080/02660830.2018.1520017.

Boyadjieva, P., and P. Ilieva-Trichkova. 2018. "Lifelong Learning as an Emancipation Process: A Capability Approach.” In Palgrave International Handbook on Adult and Lifelong Education and Learning, edited by M. Milana, S. Webb, J. Holford, R. Waller and P. Jarvis, 267-288. New York: Palgrave McMillan.

Bussing, A. 1999. "Can Control at Work and Social Support Moderate Psychological Consequences of Job Insecurity? Results from a Quasi-experimental Study in the Steel Industry.” European Journal of Work and Organizational Psychology 8 (2): 219-242.

Chung, H., and W. van Oorschot. 2011. "Institutions versus Market Forces: Explaining the Employment Insecurity of European Individuals During (the Beginning of) the Financial Crisis.” Journal of European Social Policy 21 (4): 287-301.

Crocker, D., and I. Robeyns. 2009. “Capability and Agency.” In Amartya Sen, edited by Ch. Morris, 60-90. Cambridge: Cambridge University Press.

de Lange, M., M. Gesthuizen, and M. H. J. Wolbers. 2014. "Youth Labour Market Integration Across Europe. The Impact of Cyclical, Structural, and Institutional Characteristics, European Societies 16 (2): 194-212.

De Witte, H., and K. Näswall. 2003. “Objective vs. Subjective Job Insecurity: Consequences of Temporary Work for Job Satisfaction and Organisational Commitment in Four European Countries.” Economic and Industrial Democracy 24 (2): 149-188.

Dingeldey, I., B. Hvinden, Ch. Hyggen., J. O’Reilly, and M. A. Schøyen. 2015. Deliverable 2.1 Understanding the Consequences of Early Job Insecurity and Labour Market Exclusion: The Interaction of Structural Conditions, Institutions, Active Agency and 
Capability. Available at: https://negotiate-research.eu/files/2015/04/NEGOTIATEworking-paper-no-D2.1-1.pdf

Drèze, J., and A. Sen. 2002. India: Development and Participation. New Delhi: Oxford University Press.

Drydakis, N. 2014. The Effect of Unemployment on Self-Reported Health and Mental Health in Greece from 2008 to 2013: A Longitudinal Study Before and During the Financial Crisis. Discussion Paper No. 8742. Available at: http://ftp.iza.org/dp8742.pdf

Eurostat 2017. Unemployment Statistics. Available at: http://ec.europa.eu/eurostat/statisticsexplained/index.php/Unemployment_statistics

Hvinden, B., and R. Halvorsen. 2017. "Mediating Agency and Structure in Sociology: What role for Conversion Factors?" Critical Sociology 1-16 (Online First).

Robeyns, I. 2005. "The Capability Approach: A Theoretical Survey." Journal of Human Development 6 (1): 93-114.

Robeyns, I. 2017. Wellbeing, Freedom and Social Justice. The Capability Approach ReExamined. Cambridge: Open Book Publishers.

Roosmaa, E.-L., and E. Saar. 2016. “Adults Who Do Not Want to Participate in Learning: A Cross-national European Analysis of Their Perceived Barriers.” International Journal of Lifelong Education 36 (3): 254-277.

Rubenson, K., and R. Desjardins. 2009. "The Impact of Welfare State Regimes on Barriers to Participation in Adult Education: A Bounded Agency Model.” Adult Education Quarterly 59 (3): 187-207.

Schoon, I. 2018. “Conceptualising Learner Agency: A Socio-Ecological Developmental Approach", published by the Centre for Learning and Life Chances in Knowledge Economies and Societies. Available at: www.llakes.ac.uk. 
Sen, A. 1985. "Well-being, Agency and Freedom: The Dewey Lectures 1984." The Journal of Philosophy 82 (4): 169-221.

Sen, A. 1992. Inequalities Reexamined. Oxford: Clarendon Press.

Sen, A. 1993. “Capability and Well-being.” In The Quality of Life, edited by M. Nussbaum and A. Sen, 30-53. Oxford: Clarendon Press.

Sen, A. 1999. Development as Freedom. New York: Anchor Books.

Sen, A. 2009. The Idea of Justice. Cambridge, Massachusetts: The Belknap Press of Harvard University Press.

Tolgensbakk, I., Vedeler, J. S., and B. Hvinden. 2017. NEGOTIATE working paper no. 4.4. Youth unemployment and the consequences for life satisfaction and social trust in seven European countries. Available at: https://negotiateresearch.eu/files/2015/04/NEGOTIATE-working-paper-no-D4.4-Youthunemployment-and-the-consequences-for-life-satisfaction-and-trust.pdf.

Vaughan, R. 2007. “Measuring Capabilities: An Example from Girls' Schooling.” In Amartya Sen's Capability Approach and Social Justice in Education, edited by M. Walker and E. Unterhalter, 109-130. New York: Palgrave.

Walker, M. 2007. “Widening Participation in Higher Education: Lifelong Learning as Capability.” In Philosophical Perspectives of Lifelong Learning, edited by D. N. Aspin, 131-147. Dordrecht: Springer.

Walker, M. 2012. "Egalitarian Policy Formulation in Lifelong Learning: Two Models of Lifelong Education and Social Justice for Young People in Europe.” In Second International Handbook of Lifelong Learning, edited by D. N. Aspin, D. J. Chapman, K. Evans and R. Bagnall, 181-193. London and New York: Springer. 
Walker, M., and E. Unterhalter. 2007. “The Capability Approach: Its Potential for Work in Education.” In Amartya Sen's Capability Approach and Social Justice in Education, edited by M. Walker and E. Unterhalter, 1-18. New York: Palgrave Macmillan.

Wilson-Strydom, M. 2015. "University Access and Theories of Social Justice: Contributions of the Capabilities Approach." Higher Education 69 (1): 143-155. 
Table 1. Type of actions and agency achievements with regard to continuing education.

\begin{tabular}{|c|c|}
\hline Type of actions & Agency achievements \\
\hline $\begin{array}{l}\text { - Going back to school to finish interrupted } \\
\text { educational programme/degree }\end{array}$ & $\begin{array}{l}\text { - Improving knowledge and } \\
\text { skills }\end{array}$ \\
\hline - Enrolling in /completing an educational degree & - Improving professional \\
\hline higher than that already completed & qualification \\
\hline - Enrolling in /completing a specialty other than & - Developing self-concept \\
\hline that already completed & - Raising self-esteem and \\
\hline - Enrolling in /completing a certified vocational & self-confidence \\
\hline program/course & - Increasing personal \\
\hline - Enrolling in /completing courses for acquiring & autonomy \\
\hline transferable skills (language, computer, etc.) & - Empowering one to make \\
\hline - Taking out a loan to complete the desired & decisions \\
\hline educational level or specialty & - Empowering one to control \\
\hline $\begin{array}{l}\text { - Becoming involved in workplace learning with } \\
\text { an in-company trainer/mentor }\end{array}$ & his/her environment \\
\hline $\begin{array}{l}\text { - Undertaking purposeful informal learning (e.g., } \\
\text { language learning) }\end{array}$ & \\
\hline
\end{tabular}


Table 2. Factors hindering young people's agency with regard to continuing education at the micro, meso and macro levels.

\begin{tabular}{|l|l|l|}
\hline Micro-level (individual) & Meso-level (institutional) & Macro-level (national) \\
\hline - Lack of required level of & - Ineffectiveness and low & - Lack of correspondence \\
- Insufficient learning & quality of training and & between national \\
skills/abilities & educational programmes & education policies and \\
- Lack of motivation and self- & for the unemployed at & labour market demands \\
confidence & regional/district level & national system for \\
- Family problems and & - Lack of diversity of & validating non-formal and \\
responsibilities & educational offers at & informal learning \\
- Health problems & institutional/regional level & \\
- Juvenile delinquency & - Underdeveloped & \\
& infrastructure at & institutional and \\
& regional/district level & \\
& & \\
\end{tabular}


